\title{
Normal and abnormal liquor volume and its correlation with perinatal outcome
}

\author{
Sharmila Ravi, Allirathinam, Senthil Priya, Prema Priya, Shankar Radhakrishnan \\ Correspondence: Dr Sharmila Ravi, Postgraduate, Department of Obstetrics and \\ Gynaecology , Vinayaka Mission's Kirupananda Variyar Medical College, Salem - 636308 \\ India; Email - shnkr_radhakrishnan@yahoo.com
}

Distributed under Attribution-NonCommercial-ShareAlike 4.0 International (CC BY-NC-SA 4.0)

\begin{abstract}
Aim: To assess and compare the perinatal outcome among mothers with normal and abnormal amniotic fluid volume. Methodology: A prospective comparative study was conducted for a period of one year from January 2016 to December 2016. Group I consist of 50 patients with normal amniotic fluid and group II consists of 50 patients with either oligohydramnios or polyhydramnios. Amniotic fluid index (AFI) was calculated using Phalen's four quadrant technique using ultrasound. The perinatal outcome was judged by assessing the fetal distress predicted by abnormal fetal heart rate (FHR) or meconium stained liquor, one minute and 5 minute Apgar score, frequency of admission to neonatal intensive care unit (NICU), baby weight of less than 10th percentile for gestation age and perinatal mortality. Results: Induction of labour, caesarean section and meconium stained liquor was found to be most common among the patients in group II (abnormal AFI) in comparison with normal AFI subjects and similarly the perinatal outcome measures like low birth weight, increased frequency of admission to NICU due to respiratory distress and a low APGAR score was more commonly found in abnormal AFI group and the difference was found to be statistically significant. Conclusion: AFI measurement in antepartum or intrapartum period can help to identify women who need increased antepartum surveillance for pregnancy complications and such women should be managed in a special unit to combat the complications effectively.
\end{abstract}

Keywords: Amniotic fluid index, perinatal outcome, oligohydramnios, polyhydramnios.

Modern obstetrics is more concerned with the health and wellbeing of both the mother and the unborn child. Recognition of a fetus at risk for death or damage in utero, quantifying the risk, balancing the fetal risk against the risk of neonatal complications from immaturity, and determining the optimal time and mode of intervention are the cornerstones of modern perinatal medicine. ${ }^{1}$ Clinical estimation of amniotic fluid volume (AFV) is one of the important part of fetal assessment as variation in its amount has been related to a variety of pregnancy complications including intra-uterine death. Amniotic fluid acts as a protective milieu for the growing fetus, cushioning it against mechanical and biological injury in such a way it prevents the compression of the umbilical cord, placenta and protects the fetus from vascular and nutritional compromises. ${ }^{2,3}$

Received: $10^{\text {th }}$ April 2018. Accepted: $9^{\text {th }}$ August 2018.

Ravi S, Allirathinam, Priya S, Priya P, Radhakrishnan S. Normal and abnormal liquor volume and its correlation with perinatal outcome. The New Indian Journal of OBGYN. 2019; 5(2): 113-9 
The New Indian Journal of OBGYN. 2019 (January-June); 5(2)

In 1989, Brace and Wolf had demonstrated the progressive increase of AFV starting from 10 to 22weeks of gestation and later on from 22 to 39 weeks gestation the AFV remained stable (averaging $777 \mathrm{ml}$ with a $95 \%$ confidence interval of 302 to $1997 \mathrm{ml}$ ) and then onwards it starts gradually declining. ${ }^{4}$ The average amniotic fluid volume was approximately $7 \mathrm{ml}$ at 8 weeks, $30 \mathrm{ml}$ by 10 weeks, $190 \mathrm{ml}$ by 16 weeks and $780 \mathrm{ml}$ by $32-35$ weeks then decreasing to about $400-450 \mathrm{ml}$ by 42 weeks of gestation. After 40 weeks amniotic fluid decreases at a rate of $8 \%$ per week and averages only $400-450 \mathrm{ml}$ at the end of the 42 weeks. It reduces further to a mean of $250 \mathrm{ml}$ and $160 \mathrm{ml}$ at 43 and 44 weeks respectively. The net turnover of amniotic fluid is about $1000 \mathrm{ml} /$ day. ${ }^{5}$

Quantification of amniotic fluid is an important component of the biophysical profile in ultrasound evaluation of fetal wellbeing, especially in the third trimester. ${ }^{6}$ Antenatal tests use amniotic fluid volume as a fundamental assessment of chronic in utero stress. Ultrasound being a non-invasive test is ideal for application on a large scale and can be used frequently for repeat AFV determination in the cases of suspected abnormalities. Links have been found between decreased amniotic fluid volume and stillbirths, fetal anomaly, abnormal FHR tracings in labor, increase in cesarean section for fetal distress, and possibly fetal acidosis. ${ }^{7}$ Over the past decades, a number of sonographic methods have been used to measure the amniotic fluid. Phelan et al described quantification of amniotic fluid using the amniotic fluid index (AFI). ${ }^{8}$ The four-quadrant technique termed AFI is in which a vertical pocket of amniotic fluid, free of umbilical cord, in each of four equal uterine quadrant was summated. An amniotic fluid volume more than two standard deviation below the mean for specific gestational age or volume reduced below the 5th percentile for particular gestational age would define oligohydramnios. Based on this definition, volume $<300 \mathrm{ml}$ at term would constitute oligohydramnios. ${ }^{9}$ According to Phelan et al oligohydraminos is defined by AFI $<5 \mathrm{~cm} .{ }^{10}$

Studies had been conducted for assessing the correlation between the AFV and the foetal outcome but very few studies had been carried out in this part of world and so the present study was done to assess the foetal outcome among the mothers with oligo or polyhydramnios in comparison with normal AFV.

\section{Methodology}

A prospective comparative study was conducted in our hospital for a period of one year from Jan 2016 to Dec 2016. The study was started after getting the clearance from the institutional ethical committee. A non-random purposive sampling was followed to select the 100 study subjects, which was divided into two groups of 50 each. Group I consist of 50 patients with normal amniotic fluid and group II consists of 50 patients with either oligohydramnios or polyhydramnios. The inclusion criteria for group I includes normal AFI of 5 to $24 \mathrm{cms}$ and for group II, AFI either $<5$ or $>25 \mathrm{cms}$ were included for the study. Among all singleton term pregnancies only those with intact membranes were included in the study. Pregnancy with congenital anomaly, premature rupture of membranes, multiple pregnancy, post term pregnancy and malpresentations were excluded from the study. After obtaining the informed consent from the patients a detailed clinical history including their demographic details were obtained from all the patients. Routine blood investigations were performed. A complete obstetric examination including per-vaginal examination were conducted. AFI assessment was done by the following method. The patient was made to lie in supine position; a linear or curvilinear ultrasound probe was used. Uterus was divided into 4 quadrants using the maternal sagittal midline vertically and an arbitrary transverse line approximately halfway between symphysis pubis and upper edge of uterine fundus. Transducer was kept parallel to the maternal sagittal plane and perpendicular to the maternal coronal plane throughout the process. The deepest unobstructed (free of umbilical cord or fetal parts) and clear pocket of amniotic fluid is visualized and the image was frozen. Ultrasound calipers were manipulated to measure the pocket in a strictly vertical direction. The same process was repeated in all four quadrants and it was summed to get the AFI. When the AFI was less than 8, the four quadrant evaluation was performed 3 times and the average was taken as the final reading.

The perinatal outcome was judged by assessing the fetal distress predicted by abnormal FHR or meconium stained liquor, one minute and 5 minute Apgar score judged by paediatrician, frequency of admission to NICU, 
baby weight of less than 10th percentile for gestation age and perinatal mortality. All data were entered and analyzed using SPSS version 21. Mean and SD were derived for all the parametric variables. Chi square test was carried out at $5 \%(0.05)$ level of significance to derive the statistical inference.

\section{Results}

The age wise distribution of the study subjects was shown in table 1. It is seen from the table that majority of the study subjects in both the groups were in the age group between 21 and 30 years and the mean age was 22.6 among group I patients and it was 23.5 among group II patients, there was no statistical significant difference in the age between the two groups.

Among our study subjects 46 were primigravida and the remaining 54 were multigravida and it was almost equally distributed between the two groups. Similarly the mean gestational age was between 38 to 40 weeks among both the groups and no statistical significant difference was observed between the groups with respect to gestational age and the gravida and the distribution of the consanguinity history of marriage was also equal in both the groups. The abnormal amniotic fluid index was classified as $<5$ (oligohydramnios) and more than 25 (polyhydramnios) and among the abnormal AFI, 74\% of the subjects were Table 3: Distribution of the oligohydramnios and $26 \%$ were polyhydramnios (table2).

In our study the most common cause for the abnormal AFI was found to be idiopathic followed by anaemia, gestational hypertension, hypothyroidism and gestational diabetes particularly among polyhydramnios. Almost all the subjects in the control group showed the colour of liquor to be colourless whereas $22 \%$ of the subjects with abnormal AFI showed meconium stained liquour and in that majority were having AFI $<5$ (oligohydramnios) and the difference was found to be statistically significant (table 3). The ultrasonogram doppler velocimetry had shown that there was no difference in the distribution of normal and abnormal doppler between the two groups.
The nature of labour was found to be spontaneous in more than $50 \%$ of the study subjects in normal AFI group whereas in abnormal AFI group it was only $28 \%$ and for the remaining subjects the labour was induced. The most common drug used for inducing the labour was oxytocin and the difference was found to be statistically significant.

Table 1: Age wise distribution of the study subjects

\begin{tabular}{lllll}
\hline Age group & $\begin{array}{l}\text { Group I } \\
\text { (Normal } \\
\text { AFI) }\end{array}$ & $\begin{array}{l}\text { Group II } \\
\text { (Abnormal } \\
\text { AFI) }\end{array}$ & $\begin{array}{l}\text { Chi- } \\
\text { square } \\
\text { value }\end{array}$ & $\begin{array}{l}\text { P } \\
\text { value }\end{array}$ \\
& No (\%) & Frequency & & \\
\hline $18-20$ & $7(14 \%)$ & $2(4 \%)$ & 3.73 & 0.443 \\
$21-30$ & $41(82 \%)$ & $45(90 \%)$ & & \\
Above 30 & $2(4 \%)$ & $3(6 \%)$ & & \\
Mean \pm SD & $\begin{array}{l}22.65 \pm 3.5 \\
\text { Total }\end{array}$ & $23.51 \pm 2.86$ & & \\
\hline
\end{tabular}

Table 2: Distribution of the study subjects according to their AFI

\begin{tabular}{lll}
\hline AFI & $\begin{array}{l}\text { Group I } \\
\text { (Normal AFI) } \\
\text { No (\%) }\end{array}$ & $\begin{array}{l}\text { Group II } \\
\text { (Abnormal AFI) } \\
\text { No (\%) }\end{array}$ \\
\hline$<5 \mathrm{cms}$ & 0 & $37(74 \%)$ \\
$6-25 \mathrm{cms}$ & $50(100 \%)$ & 0 \\
$>25 \mathrm{cms}$ & 0 & $13(26 \%)$ \\
Total & $50(100 \%)$ & $50(100 \%)$ \\
\hline
\end{tabular}

\begin{tabular}{lllllll}
\hline \multirow{2}{*}{$\begin{array}{l}\text { Colour of } \\
\text { Liquor }\end{array}$} & $\begin{array}{l}\text { Oligohydr- } \\
\text { amnios } \\
\text { (Group II) }\end{array}$ & $\begin{array}{l}\text { Polyhydra- } \\
\text { mnios } \\
\text { (Group II) }\end{array}$ & $\begin{array}{l}\text { Control } \\
\text { (Group I) }\end{array}$ & Total & $\begin{array}{l}\text { Chi } \\
\text { square }\end{array}$ & P Value \\
\cline { 2 - 4 } & $\mathbf{N}(\%)$ & $\mathbf{N}(\%)$ & $\mathbf{N}(\%)$ & & & \\
\hline $\begin{array}{l}\text { Colourless } \\
\text { Meconium } \\
\text { stained liquor } \\
\text { Total }\end{array}$ & $27(73 \%)$ & $12(92 \%)$ & $50(100 \%)$ & 89 & & \\
\hline
\end{tabular}

Seventy eight percent in normal AFI group had a full term normal delivery (FTND) compared to only $24 \%$ with abnormal AFI had FTND and this difference was found to be statistically significant.

Among the mode of delivery the most common mode of delivery among the group I patients was normal vaginal delivery whereas among the group II patients it was caesarean section and in that majority of them were taken for emergency caesarean section and the difference was found to be statistically significant (table 4). Of the foetal 
Table 4: Distribution of the study subjects according to their spontaneous labour and mode of delivery

\begin{tabular}{lllll}
\hline Variables & $\begin{array}{l}\text { Group I } \\
\text { (Normal } \\
\text { AFI) } \\
\text { No (\%) }\end{array}$ & $\begin{array}{l}\text { Group II } \\
\text { (Abnormal } \\
\text { AFI) }\end{array}$ & $\begin{array}{l}\text { Chi- } \\
\text { square }\end{array}$ & $\begin{array}{l}\text { P } \\
\text { value }\end{array}$ \\
& & & \\
Spontaneous & & & \\
labour & $27(54 \%)$ & $14(28 \%)$ & 18.76 & $<.001$ \\
FTND & $39(78 \%)$ & $12(24 \%)$ & 29.49 & $<.0001$ \\
\hline
\end{tabular}

distress syndrome followed by hyperbilirubinemia (table $5)$. The mean birth weight of the newborn in group I was found to be within normal limits whereas the birth weight of the newborns among the mothers with oligohydramnios was lesser than the normal and among the polyhydramnios it was higher than the normal and the difference was found to be statistically significant (table 6). Similarly the APGAR score was higher among babies with mothers having normal AFI both at $1 \mathrm{~min}$ and $5 \mathrm{mins}$ after birth compared to babies born to mothers with

Table 5: Various causes for NICU admission among the study subjects

\begin{tabular}{|c|c|c|c|c|c|c|}
\hline \multirow[t]{2}{*}{$\begin{array}{l}\text { Reasons for NICU } \\
\text { admission }\end{array}$} & \multicolumn{2}{|c|}{$\begin{array}{l}\text { Group I (normal AFI) } \\
\quad(n=50)\end{array}$} & \multicolumn{2}{|c|}{$\begin{array}{l}\text { Group II (abnormal } \\
\text { AFI) } \quad(n=50)\end{array}$} & \multirow[t]{2}{*}{$\begin{array}{l}\text { Chi- } \\
\text { square }\end{array}$} & \multirow[t]{2}{*}{$\begin{array}{l}\mathbf{P} \\
\text { value }\end{array}$} \\
\hline & Frequency & Percentage & Frequency & Percentage & & \\
\hline Hyperbilirubinemia & 1 & $2 \%$ & 4 & $8 \%$ & & \\
\hline Hypoglycemia & 0 & 0 & 2 & $4 \%$ & 10.67 & 0.014 \\
\hline $\mathrm{RDS}$ & 4 & $8 \%$ & 8 & $16 \%$ & & \\
\hline IUGR & 1 & $2 \%$ & 2 & $4 \%$ & & \\
\hline Total & 6 & $12 \%$ & 16 & 32 & & \\
\hline
\end{tabular}

Table 6: Distribution of the study subjects based on their birth weight

\begin{tabular}{|c|c|c|c|c|c|c|c|}
\hline \multirow{2}{*}{$\begin{array}{l}\text { Birth Weight } \\
\text { in Kg }\end{array}$} & \multicolumn{2}{|c|}{$\begin{array}{l}\text { Oligohydramnios } \\
\text { (Group II) }\end{array}$} & \multicolumn{2}{|c|}{$\begin{array}{l}\text { Polyhydramnios } \\
\text { (Group II) }\end{array}$} & \multicolumn{2}{|l|}{ Group I } & \multirow[t]{2}{*}{$P$ value } \\
\hline & Frequency & $\%$ & Frequency & $\%$ & Frequency & $\%$ & \\
\hline $1.5-2$ & 1 & $3 \%$ & 0 & 0 & 0 & 0 & \\
\hline $2-2.5$ & 6 & $16 \%$ & 1 & $8 \%$ & 0 & 0 & \\
\hline $2.5-3$ & 28 & $76 \%$ & 3 & $23 \%$ & 36 & $72 \%$ & \\
\hline $3-3.5$ & 2 & $5 \%$ & 6 & $46 \%$ & 14 & $28 \%$ & \\
\hline$>3.5$ & 0 & 0 & 3 & $23 \%$ & 0 & 0 & $<.001$ \\
\hline Total & 37 & $100 \%$ & 13 & $100 \%$ & 36 & $100 \%$ & \\
\hline Mean \pm SD & $2.16 \pm 0.81$ & & $3.52 \pm 0.74$ & & $2.51 \pm 0.93$ & & $<.0001^{*}$ \\
\hline
\end{tabular}
abnormal AFI for whom the APGAR score was less and the difference was found to be statistically significant (table 7).

Discussion

The present study was carried out to assess the effectiveness of measuring the AFI and its association with maternal and foetal outcome during the time of labour. In the present study the mean age of the mothers in both the groups were between 23 to 24 years and the results are in comparable to the study conducted by Ghike et al where he found the mean age of women in study group was 24.65 years and among controls it was 24 years. $^{11}$ In our study we found that the distribution of primi gravida and multi gravid among both the groups were almost equal

outcome 6 neonate in group I and 16 neonates in group II got admitted in NICU post-delivery and the difference was found to be statistically significant and the common reasons for getting admitted in NICU were respiratory in numbers and the mean gravida was found to be 1.6 which is comparable to the study done by Baron et $\mathrm{al}^{12}$ in which he quoted that the mean gravida of his study subjects was 2 and another study done by Monica 
The New Indian Journal of OBGYN. 2019 (January-June); 5(2)

Chetani where they found the mean gravida as $1.7 .{ }^{13}$ In the current study $60 \%$ of oligohydramnios were primigravida and it was similar to the results derived by Garmel et al ${ }^{14}$ in which they observed that $67 \%$ were primigravida and in the study done by Monica Chetani it was $63 \%{ }^{13}$

The mean gestational age in our study was 38.42 weeks in study group and 38.64 weeks in control group which is in par with the mean gestational age of 37.5 weeks in a study done by Casey et al. ${ }^{15}$ There was no significant difference according to gestational age in our study and control groups. In the current study we found that meconium stained liquor was more common among the abnormal AFI group when compared to the normal AFI and the difference was found to be statistically significant. Our study was well supported by Crowley et al, who found statistically significant increase in MSL in patients with reduced amniotic fluid volume. ${ }^{16}$ Similarly, Rutherford et $\mathrm{al}^{17}$, Ergun et $\mathrm{al}^{18}$, Magann et $\mathrm{al}^{19}$, Casey et $\mathrm{al}^{15}$, also observed that MSL was significantly higher in patients with oligohydramnios as compared with normal amniotic fluid index, whereas a study conducted by Voxman et al concluded that there was no difference between the groups with regard to meconium-stained liquor. $^{20}$

In present study, induction of labour was more in oligohydramnios group than that in control group and the difference was found to be highly significant $(\mathrm{p}<0.001)$ and a similar association was also seen in the study done by Casey et $\mathrm{al}^{15}$, in which they found that the rate of induction in patients with oligohydramnios as $42 \%$ and similar studies done by Rainford et al, Jandial et al, Gumus et al had also substantiated the findings. ${ }^{21-23}$ Literatures had quoted that uteroplacental insufficiency and fetal compromise might be the reasons for the higher rate of induction in pregnancy with oligohydramnios.

Chauhan et al. ${ }^{24}$ in their meta-analysis found that intrapartum $\mathrm{AFI} \leq 5$ was associated with increased risk of cesarean section for fetal distress (pooled $R R=1.7$ ), which was similar to our study, whereas as an inverse relationship between amniotic fluid index and cesarean section for fetal distress was observed in a study done by Rutherford et al. ${ }^{17}$ In the studies conducted by Sarno et al, Conway et al and Sriya, the rate of LSCS for fetal distress was higher in abnormal AFI group when compared to normal AFI group which is similar to present observation. ${ }^{25-27}$

Incidence of low birth weight (birth weight $<2.5 \mathrm{~kg}$ ) was $20 \%$ in the study group compared to $0 \%$ in the control group and the difference was found to be statistically highly significant $(\mathrm{p}<0.001)$ and a similar results was mentioned in a study done by Ghike et al. ${ }^{11}$ The reasons for low birth weight in patients having reduced AFI are either due to preterm birth or chronic placental insufficiency leading onto IUGR. In the current study we found a higher rate of admissions to NICU among the newborn babies delivered by the mother's with low AFI and the difference was found to have statistically significant association when compared to mothers with normal AFI and a similar type of results were reported in the studies done by by Voxman et al, Gumus et al and Jandial et al. ${ }^{20,22,23}$ With relation to APGAR score we found a poor APGAR score at $1 \mathrm{~min}$ and 5 mins after birth among the babies delivered with abnormal AFI when compared to normal AFI and the difference was found to be statistically significant and it is in par with the results quoted by Grubb et al and Morris et al. ${ }^{28,29}$

\section{Conclusion}

Abnormal AFI is associated with increased rate of pregnancy related complication like increased chance of inducing labour, meconium stained liquor, LSCS and increased perinatal morbidity like low birth weight, low APGAR score and higher incidence of respiratory distress syndrome leading on to the admission in NICU. So, AFI measurement in antepartum or intrapartum period can help to identify women who need increased antepartum surveillance for pregnancy complications and such women should be managed in a special unit to combat the complications effectively.

\section{Conflict of interest: None. Disclaimer: Nil.}

\section{References}

1.Manning FA. Antepartum fetal testing: a critical appraisal. Curr Opin Obstet Gynecol. 2009; 21(4): 348-52.

2.Chamberlain PF, Manning FA, Morrison I, Harman CR, Lange IR. The relationship of marginal and decreased amniotic fluid volumes to perinatal outcome. Am J Obstet Gynecol. 1984;150(3):245-9. 
3.Nageotte MP, Towers CV, Asrat T, Freeman RK. Perinatal outcome with the modified biophysical profile. Am J Obstet Gynecol. 1994;170(6):1672-6.

4.Brace RA, Wolf EJ. Normal amniotic fluid volume changes throughout pregnancy. Am J Obstet Gynecol. 1989; 161: $382-8$.

5.Arias F. Practical guide to high risk pregnancy and delivery. 2nd ed. Missouri: Mosby; 1993.

6.Kofinas A, Kofinas G. Differences inamniotic fluid patterns and fetal biometric parameters in third trimester pregnancies with and without diabetes. J Matern Fetal Neonatal Med. 2006; 19(10): 633-8.

7.Pauer HU, Viereck, Krauss V, Osmers R, Krauss T. Incidence of fetal malformations in pregnancies complicated by oligo and polyhydramnios. Archives of Gynecology and obstetrics. 2003; 268(1): 52-6.

8.Thompson O, Brown R, Gunnarson G, Harrington K. Prevalence of polyhydramnios in third trimester in a population screened by first and second trimester ultrasonography. Journal of Perinatal Medicine. 1998; 26(5): 371-7.

9.Dashe JS, Mclntire DD, Ramus RM, Santos Ramos R, Twickler DM. Hydramnios: anomaly prevalence and sonographic detection. Obstetrics and Gynecology. 2002; 100 (1): 134-9.

10.Phelan JP, Smith CV, Small M. Amniotic fluid volume assessment with four quadrant technique at 36-42 weeks of gestation. J Reprod Med. 1987; 32(7): 540-2.

11.Ghike S, Reddy G, Ghike NW. Increasing severity of oligohydramnios: A risk factor for outcome. J South Asian Feder Obst Gynecol. 2013; 5(1): 8-10.

12.Collen B, Morgan MA, Garite TJ. The impact of amniotic fluid volume assessed intrapartum on perinatal outcome. Am J Obstet Gynecol. 1995; 173(1): 167-74.

13.Chetani M, Deepika, Khajotia S, Kochar S. A Clinical study of amniotic fluid index at or beyond 28 weeks of gestation and its relation to perinatal outcome. Int $\mathrm{J}$ Reprod Contracept Obstet Gynecol. 2017; 6(8): 3280-6.

14.Garmel SH, Chelmow D, Sha SJ. Oligohydramnios and appropriately grown fetus. Am J Perinatol. 1997; 14(6): 35963.

15.Casey BM, Mc-Intire DD, Donald D. Pregnancy outcome after diagnosis of oligohydramnios at or beyond 34 weeks of gestation. Am J Obstet Gynecol. 2000; 182(4): 902-12.

16.Crowley P, Harlihy CO, Boylan O. The value of ultrasound measurement of amniotic fluid volume in the management of prolonged pregnancies. Br J Obstet Gynecol. 1984; 91(5): 444-8.

17.Rutherford SE, Jeffrey P, Phelan J, Smith CV, Jacobs N. The four quadrant assessment of amniotic fluid volume. An adjunct to antepartum fetal heart rate testing. Obstet Gynecol. 1987; 70(3 Pt 1): 353-6.

18.Ergün A, Atay V, Pabuçcu R, Başer I, Duru NK, Tokaç G. Predictive value of amniotic fluid volume measurements on perinatal outcome. Gynecol Obstet Invest. 1998; 45(1): 19-23.

19.Magann EF, Chouhan SP, Kinsella MJ. Antenatal testing among 1001 patients at high risk. The role of ultrasonographic estimate of amniotic fluid volume. Am J Obstet Gynecol. 1999; 180: 1330-6.

20.Voxman EG, Tran S, Wing DA. Low amniotic fluid index as a predictor of adverse perinatal outcome. J Perinatol. 2002; 22(4): 282-5.

21.Rainford M, Adair R, Scialli AR, Ghidini A, Spong CY. Amniotic fluid index in the uncomplicated term pregnancy. Prediction of outcome. J Reprod Med. 2001; 46(6): 589-92.

22.Jandial C, Gupta S, Sharma S, Gupta M. Perinatal outcome after antepartum diagnosis of oligohydramnios at or Beyond 34 weeks of gestation. JK Sci. 2007; 9(4): 213-4.

23.Gumus II, Koktener A, Turhan NO. Perinatal outcomes of pregnancies with borderline amniotic fluid index. Arch Gynecol Obstet. 2007; 276(1):17-9.

24.Chauhan SP, Sanderson M, Hendrix NW, Magann EF, Devoe LD. Perinatal outcome and amniotic fluid index in the antepartum and intrapartum periods: a meta-analysis. Am J Obstet Gynecol. 1999; 181(6): 1473-8.

25.Sarno AP Jr, Ahn MO, Brar HS, Phelan JP, Platt LD. Intrapartum Doppler velocimetry, amniotic fluid volume and fetal heart rate as prediction of subsequent fetal distress. Am J Obstet Gynecol. 1989; 161 (6 Pt 1): 1508-14.

26.Conway DL, Adkins WB, Shroedere B. Isolated oligohydramnios in the term pregnancy: Is it a clinical entity? J Matern Fetal Med. 1998; 7(4): 197-200.

27. Sriya R, Singhai S. Perinatal outcome in patients with amniotic fluid index $<5 \mathrm{~cm}$. J Obstet gynecol India. 2001; 51(5): 98-100.

28.Grubb DK, Paul RH. Amniotic fluid index and prolonged antepartum fetal heart rate decelerations. Obstet Gynecol. 1992; 79(4): 558-60.

29.Morris JM, Thompson K, Smithey J, Gaffney G, Cooke I, Chamberlain P, Hope P, et al. The usefulness of ultrasound assessment of amniotic fluid in predicting adverse outcome 
The New Indian Journal of OBGYN. 2019 (January-June); 5(2)

in prolonged pregnancy: a prospective blinded observational study. Br J Obstet Gynaecol. 2003; 110(11) :989-94.

Sharmila Ravi ${ }^{1}$, Allirathinam ${ }^{2}$, Senthil Priya ${ }^{3}$, Prema Priya $^{4}$, Shankar Radhakrishnan ${ }^{5}$

${ }^{1}$ Postgraduate Student, Obstetrics and Gynaecology;
${ }^{2}$ Prof and Head, Obstetrics and Gynaecology;

${ }^{3}$ Associate Professor, Obstetrics and Gynaecology;

${ }^{4}$ Assistant Professor, Obstetrics and Gynaecology; ${ }^{5}$ Associate Professor, Department of Preventive Medicine, Vinayaka Mission's Kirupananda Variyar Medical College, Salem - 636308 